\title{
21 INFORMATION TECHNOLOGY OUTSOURCING IN THE SERVICE ECONOMY: Client Maturity and Knowledge/Power Asymmetries
}

\author{
Aris Komporozos-Athanasiou \\ Judge Business School \\ University of Cambridge \\ Cambridge, U.K.
}

\begin{abstract}
The service economy calls for a new, interdisciplinary methodology for defining and valuing information technology services outsourcing needs. Parameters such as ill-informed provider selection and poor contract management have hitherto dominated the IT consulting literature, yet have offered inadequate explanations to the high failure rates in global outsourcing arrangements. This paper takes a different approach in examining the causes of the problem; we discuss the knowledge and power asymmetries that appear to prevent both parties from realizing potential benefits in the market. The concept of self-knowledge as opposed to relationship management is suggested. We posit that knowledge/power asymmetries can be better comprehended when the two parties are considered as interacting entities that influence each other in a dynamic way. Under this spectrum, we discuss the value of a clientfocused maturity assessment in realizing potential outsourcing benefits.
\end{abstract}

Keywords Outsourcing, knowledge and power, client maturity, asymmetries, coevolution

\section{IT OUTSOURCING: RELATIONSHIP MANAGEMENT VERSUS SELF-KNOWLEDGE}

The scale of outsourcing arrangements has grown exponentially over the last 10 years. It has come to include a significant transfer of assets and staff to a vendor who

Please use the following format when citing this chapter:

Komporozos-Athanasiou, A., 2008, in IFIP International Federation for Information Processing, Volume 267, Information Technology in the Service Economy: Challenges and Possibilities for the $21^{\text {st }}$ Century, eds. Barrett, M., Davidson, E., Middleton, C., and DeGross, J. (Boston: Springer), pp. 301-310. 
assumes profit and loss responsibility. The resulting $\$ 200$ billion market offers possibilities for significant cost saving, improvement in agility, control, and risk exposure. However, a large number of outsourcing arrangements fail to secure the agreed deliverables, often resulting in a lose-lose situation for both the service provider and the service recipient. It is estimated that the United Kingdom alone has wasted $\$ 18$ billion on failed information technology outsourcing projects. ${ }^{1}$

What is more, outsourcing has come to constitute a much more dynamic and complex activity in the service economy. Knowledge creation, sharing and diffusion are of key value to understanding and managing an organization's outsourcing needs. Hence, sourcing decisions over business processes cannot be considered in abstraction from knowledge issues throughout the lifecycle of an outsourcing arrangement.

It is true that knowledge facets of outsourcing have generally been acknowledged in the extant literature; however, they tend to be considered mainly in relation to the transfer of IT staff and specialized know-how to the outsourcing provider. Devolution of knowledge is thought to be caused by the outsourcing arrangement itself. The prescription for the problem typically includes strategic pathways to successful outsourcing through efficient relationship management. Managing the relationship with the service provider pertains to the power side of these knowledge issues. It is also argued to be a lever for gaining power over the relationship and thus controlling the flux of knowledge capital established by service level agreement (SLA) interorganizational channels.

Nevertheless, our research points at another milieu wherein power and knowledge are manifested: the client's own organization. One could argue that it is from within the organizational boundaries that knowledge-related hydras commence. It is, in other words, the lack of self-knowledge on the client's side that prevents it from capitalizing on the (assumed) increased control over the outsourcing counterpart (provider). Vital issues such as the inability to define outsourcing needs clearly, the failure to understand and evaluate the role of different business processes, and the absence of a comprehensive view of the intra-organizational linkages, commonly result in a "rule of thumb" approach of sourcing strategy. What we will call self-knowledge is hence a conditio sine qua non for an effective engagement in an outsourcing relationship. Moreover, the informed power generated from a self-education process is key to building a mutually beneficial SLA.

Before we discuss these points in more depth, it is useful to attempt an analysis of the sourcing relationship context, the outsourcing market, and consider some interesting trends pertaining to the behavior of the involved parties.

\section{KNOWLEDGE/POWER ASYMMETRIES}

A typical outsourcing contract includes a maturity certification requirement for the service provider. Such third party validation, forced by the customer and often paid by the provider, typically involves capability maturity model (CMM) type assessments offered by organizations such as Accenture, TPI, and PricewaterhouseCoopers. Major service providers hold certifications that appear to assure risk reduction for clients and,

1“'Outsourcing Overruns Cost UK Taxpayers £9bn,” The Register, December 27, 2007, in Taylor and Toft 2008 (originally published at Kablenet (Kable's Government Computing), "Report Says Outsourcing Overuns Cost Billions," December 24, 2007. 
therefore, increase the probability of a correct solution being delivered. Furthermore, through the (repeated) process of third party certification, and as long as the validations offered are not content-free, they force an increase of knowledge on the part of the suppliers. Ergo, the client is given various options of different suppliers who insist on self-knowledge and are able to keep costs for the customer at a minimum in response time. However, looking at the outsourcing service recipient side, there is currently no form of third party validation of skills, self-knowledge, and maturity, that has achieved a degree of market penetration similar to the aforementioned provider-focused CMMtype assessments. ${ }^{2}$

Nonetheless, in an increasingly commoditized market, an apparent shift of power toward the buyer is taking place, a tendency predicted to grow in the next few years (Willcocks and Lacity 2006). The client is seemingly becoming more capable of managing the outsourcing relationship and dictating the terms and conditions of the SLA, but does this increase of customer power have an equivalence in increased (self) knowledge and, if not, does this matter? We suggest that it does not and that this leeching of understanding can be detrimental to the long-term future of an organization.

An asymmetry of power and knowledge appears to exist in the outsourcing market. The conventional view on this asymmetry suggests that it is in favor of the client. It is thus proposed that the client's control in driving and designing outsourcing deals will result in increased benefits on the service recipient side. ${ }^{3}$ From our observation of commercial and public organizations, it is arguable that the leeching of internal expertise and lack of self-understanding will at best reduce, and at worst preclude, long-term benefits. The client organizations are likely to devolve themselves of real power in the course of the outsourcing contract. In effect the asymmetries function in favor of the provider who assimilates knowledge and expertise.

This asymmetry has also resulted in a gradual saturation of the existing assessment methodologies and weakened their credibility. What is more, they have imperilled their very functionality by favoring a homogeneous, highly mature environment on the provider's side, which allows for little or no differentiation among them. Thus, even the marketing-justified purposes of the produced models are severely undermined as the client is presented with a palette of seemingly hyper-mature service providers.

\section{THE OUTSOURCING LITERATURE GAP}

Academic and best practice literature has generally assumed this conventional power view and it has thus focused on developing frameworks that address the contract signing and post-contract period of the outsourcing relationship.

${ }^{2}$ For instance, the Software Engineering Institute at Carnegie Mellon has only recently developed client CMM, which we discuss in section 3 of this paper. See also the discussion of the "peacock's tail" client-provider relationship in section 6 .

${ }^{3}$ Indicative of this view is Willcocks and Lacity's (2006) study. They present their estimations on the future of the outsourcing market, suggesting that "clients are taking more control in driving and designing outsourcing deals" (p. 279) and that "they will move en masse from "hype and fear' into maturity" by 2011 (p. 281). They subsequently suggest that providers are currently overselling (their own) capability to the outsourcing recipient and that they would need to follow a similar to the client's core competences model to match the client practices. 
Various high-level models outline strategic visions related to IT outsourcing. Scholars such as Venkatraman (1997) describe an IT organization structured according to the "value center" concept. This concept divides IT activities into four categories (service center, investment center, cost center, and profit center) that differ with regard to their purpose (business capability versus operational efficiency) and their risk propensity (minimize risk versus maximize opportunity). Such a structure of the IT organization could allow for more informed and rational IT outsourcing decisions. Moreover, decision-making frameworks have typically provided the customer with a road map to successfully establish and manage the IT outsourcing relationships. This includes actual sequences of steps or more general best practice guides such as the eight building blocks model proposed by Cullen and Willcocks (2003). Di Romualdo and Gurbaxani (1998) define three different strategic intents for IT outsourcing (IS improvement, commercial exploitation, and business impact) and outline how organizations should pursue these different intents when approaching outsourcing. Also, decision-making models such as McFarlan and Nolan's (1995) strategic grid and Kernet al.'s (2002) winner's curse provide organizations with a way of structuring the rationale underlying their outsourcing decisions. The Carnegie Mellon "eSourcing Capability Model for Client Organizations," the latest, and most coherent to date, approach in measuring outsourcing capabilities, also takes a relationship management perspective. It focuses on a set of best practice guidance throughout the life of an outsourcing arrangement, but similarly to the aforementioned models, it does not consider the organization's maturity prior to the sourcing lifecycle.

There seems to be a gap in the literature; the precontract phase of an outsourcing agreement is not covered by any of these models. In effect, no causal relationship has been probed between the organization's in-house capabilities and a successful outsourcing project. The unasked question is, what are the necessary organizational skills within the client's IT organization, before it undertakes an outsourcing project?

It can be argued that an outsourcing arrangement is more likely to deliver the expected benefits when the client already has a level of self-awareness with regard to its outsourcing capabilities. That can only be achieved by rigorous engagement in a selfeducation process, through introspection and reconsideration of the organization's IT and business capabilities.

\section{THE VALUE OF A CLIENT-FOCUSED MATURITY ASSESSMENT MECHANISM}

As has become clear from our analysis, a client-focused maturity assessment mechanism can be greatly facilitative in tackling the outsourcing market asymmetries. A third party assessment of the client's outsourcing capabilities could be developed around the information technology infrastructure library (ITIL) platform. One such attempt is the client outsourcing maturity model (COMM) developed by Komporozos-Athanasiou (2006) and Perez-Hallerbach (2007). COMM attempts to encompass a more coherent and detailed method for the examination of an organization's process maturity. Moreover, it extends the process of a focused and unidimensional ITIL in order to include softer dimensions such as governance and people. Hence, it enhances ITIL's appli- 
cability on IT services outsourcing and suggests that COMM-mature client organizations are more likely to engage in successful and mutually beneficial outsourcing agreements with a service provider (Komorozos-Athanasiou 2007).

At the process level, the model looks at issues such as the use of best practice models in IT management, the comprehension of and adherence to the service and service lifecycle concepts ${ }^{4}$ and the use of quantitative models and outsourcing frameworks in the IT organization, prior to an outsourcing engagement. The governance dimension assesses the mechanisms through which IT strategy is articulated and communicated as well as its linkages with the organization's business processes and it draws from a wide set of criteria covering, among others, an assessment of its IT investment evaluation behavior.

One should note that the COMM methodology differs from the one that processfocused models (i.e., Carnegie-Melon's CMM) commonly adopt, in that it provides a wider definition of maturity. A knowledge-based definition of maturity is adopted and hence the key notion of business and IT alignment is being examined under the spectrum of cognitive congruence (Merali 2002). COMM recognizes the importance of the service lifecycle for organizing business processes and orchestrating them around what the final product is, the service; however, it incorporates a people dimension that assesses the degree of intra-organizational understanding (among different stakeholders) of basic assumptions, concepts, values, and needs. Following the concept of $B a$ (Nonaka and Noboru 1998), which describes the shared space where knowledge is created through a process of socialization (including interfunctional communication), COMM attempts to capture the diverse interpretations throughout the organizational interactions. Furthermore, it proposes a platform for bringing together key stakeholders (user groups, finance, operations, research and development) and employs a methodology for developing analytic models that can be shared between stakeholder groups in order to enable joint exploration of design, implementation, and management issues (Taylor et al. 2004).

\section{THE ROLE OF THE SERVICE PROVIDER}

Having considered the importance of client maturity and the necessity of selfunderstanding prior to the engagement in an outsourcing relationship, we have generally assumed that high maturity characterizes the provider side. One should note that the service provider is exposed to more specialized knowledge and benefits significantly from the continuous self-assessment process (through its various certification and assessment mechanisms). However, our research indicates that this suggested maturity does not necessarily translate into mature behavior toward the client.

Often, the need for a "big bid" forces the provider to engage in a unsophisticated, commodity-based approach in its relationship with the client because the client is unprepared to assimilate a more mature level of services and services support due to its lack

${ }^{4}$ Service concept: By packaging business needs into well-defined products that are delivered by the IT organization, a basic object of interest is created that the processes within the IT organization can handle, modify, and, perhaps more importantly, talk about in a well-understood language. 
of needs understanding and internal capabilities. In such an immature business environment, any attempt to raise issues of self-awareness and knowledge diffusion within the service recipient's organization is fruitless. Consequently, providers are presented with ill-defined outsourcing needs, which are then poorly addressed. No attempt is made to draw the client's attention to its inability to understand and thereby define its needs in a comprehensive fashion, not least for fear of losing the deal; a "quick fix" solution is preferred instead. We hence observe the development of a vicious circle of low maturity throughout the client-provider relationship, which commences well before the signing of the outsourcing contract, in the bidding/selection period. This attitude has come to be embedded in both parties' culture, preventing the solutions offered from providing substantial benefits and the outsourcing market as a whole from realizing potential profits.

It becomes evident from the above discussion that a service provider bears the primary responsibility in triggering a change in the mentality of both parties. An "open box" philosophy in the services provision offers the ground for such a transition to a more mature relationship context. The tools, and most importantly the mindset, this paper attempts to advocate suggest an "intelligent engagement" methodology that can (1) potentially increase the "fit for purpose" of a solution, and (2) offer a means of understanding the impact of outsourcing investment on the client's business objectives.

\section{OUTSOURCING AS A COEVOLUTIONARY RELATIONSHIP}

The asymmetries discussed above can be better comprehended when the two parties (provider and client) are considered as interacting entities that influence each other in a dynamic way. Under this spectrum, we can examine different formations of the outsourcing relationship using examples of coevolutionary contexts exhibited by biological systems.

\subsection{The Competitive Predator-Prey Relationship ${ }^{5}$}

The outsourcing relationship can take the form of a competitive predator-prey interaction, which may lead to an arms race. ${ }^{6}$ Both outsourcing counterparts are confined in a game of control over the terms and conditions of the SLA in order to maximize their own benefit, disregarding knowledge issues that pertain to the relationship. To illustrate a typical situation resulting from this relationship pattern, we cite the case of the U.S. Navy IT outsourcing deal mega-failure. EDS assumed control of all information systems and software provision for 690,000 users and 4 network operation centers at the Navy

${ }^{5}$ Here, both parties are effectively preys, as both are faced with the threat of failure. The case of "pollination" is the other form of a predator-prey pattern, where both parties engage in a symbiotic relationship.

${ }^{6}$ An evolutionary struggle between competing sets of coevolving genes that develop adaptations and counter adaptations against each other, resembling an arms race. 
and the Marine Corps. ${ }^{7}$ As of 2006, EDS had made a total provision of $\$ 875$ million against the contract, albeit failing to meet the stringent performance targets that had been included in the SLA. As a result, EDS suffered a major loss due to their failure to fully deploy their intended solutions and charge under the contract. The client seemingly managed to achieve a victory over the provider, first by imposing strict SLA terms and subsequently by financially punishing the errant supplier (Taylor and Tofts 2005). Nonetheless, neither of the two parties won in the end, insofar as the client was not receiving the services and systems needed, presumably continuing to operate with equipment they intended to replace (equipment that one can assume was not delivering the capabilities they desired).

\subsection{Pollination}

In this relationship, the outsourcing provider acts as a pollinator, transmitting the client's tacit knowledge and self-understanding to a know-how repository. This repository is continuously enriched via interaction with more clients and subsequently communicated back to the clients in the form of IT outsourcing consulting. In this case, the provider recognizes the need for dealing with an "educated" client with whom they do not solely attempt to close a deal, but rather engage in a mutually beneficial relationship (at a later stage). This type of pattern necessitates the adoption of long-term considerations and planning toward enriching the engagement by establishing knowledge sharing channels and promoting open box practices.

\subsection{The Peacock's Tail}

The peacock's tail phenomenon constitutes perhaps the most accurate analogy with the dominant form of outsourcing relationship, observed in the market: the provider adjusts its behavior to the client's selection criteria. It, therefore, seeks external maturity assessment, turning to the third party certification market to add more such qualifications to its certification arsenal. This behavior, while the client side remains out of the certification process, seemingly increases the provider's chances to be selected in an outsourcing bid. Nonetheless, as previously discussed, it is likely that this unilaterally performed behavior will effectively result in limited provider manoeuverability, and ultimately, in reduced benefits from the outsourcing arrangement. Likewise, in evolutionary biology, male peacocks develop spectacular tails, which facilitate sexual selection and are therefore considered to be an advantage in reproduction. However, the peacock's tail almost certainly reduces the male's survival: the tail reduces manoeuverability, powers of flight, and makes the bird more conspicuous (Burgess 2001). Interestingly, certain studies have moreover indicated that the peahen has little or no interest in the appearance of the peacock, insofar as there is no evidence that it can recognize subtle aesthetic features (Cronin 1991). In the outsourcing milieu, it is arguable that an immature client is not able to distinguish between providers of different maturity levels and thus the respective maturity certification often becomes a mere aesthetic feature.

${ }^{7}$ See http://www.eds.com/sites/nmci/, "Navy Marine Corp Intranet (NMCI)." 
These metaphors shed more light on a number of key issues that we have hitherto identified. In the EDI-U.S. Navy arms race case, the evident lack of self-knowledge at the pre-engagement stage on the client (U.S. Navy) side, "resulted in outsourcing a mess" (Willcocks and Lacity 2006), a state wherein the client mitigates responsibility for a business process, over which it has already lost control, and hence in contracting for services, which the organization did not have the mechanisms in place to evaluate. However, as we earlier discussed, one should not assume that the provider bears no responsibility for this lose-lose situation. Although CMM certified and mature, the provider did not appear willing to invest (and be a pollinator) in raising the client's self-awareness with regard to its own outsourcing needs. The role of the third party certifications is crucial here, since a significant flux of provider investment toward them is generated, fueling a fierce competition in the IT services market. Nonetheless, as we saw in the peacock's tail example, insofar as a similar third party validation for the client is neither available nor bilaterally accepted, these certifications will often function merely as "tranquilizers" for client companies when dealing with their outsourcing conundrums. In this context, the resulting knowledge/power asymmetries are likely to trigger a vicious circle of low maturity, which will characterize the outsourcing relationship in its later stages.

\section{CONTRIBUTION AND FUTURE RESEARCH}

The value of a maturity assessment mechanism that specifically addresses the client organization's business environment can be significant in triggering a change in the mindset of IT managers. The aim of this paper was to open a new trail in the outsourcing literature for research that includes

(1) Power and knowledge issues considered under the same analytical lens

(2) Introspection and self-education viewed as a part of the outsourcing decision-making lifecycle

(3) Knowledge asymmetries utilized as an alternative epistemological approach in explaining the unrealized outsourcing benefits

This paper has attempted to raise the managers' awareness on aspects of IT services outsourcing that have been under-considered in the extant literature. We deployed a knowledge/power lens to analyze the inter- and intra-organizational pathologies. At the market level, we attempted to reposition the current maturity debate at the client side and we underscored the inseparability of power and knowledge in the formation of the clientprovider relationship. We discussed the value of a client-focused framework (such as COMM) that points at neglected soft organizational characteristics and places issues of individual and shared understanding at the heart of its methodological platform. We then utilized the biological metaphor to illustrate how different patterns of dynamic outsourcing relationships may be observed in an asymmetrical market.

Nevertheless, the power side was only superficially considered in our intraorganizational analysis and it is undoubtedly a question that merits further investigation. Specifically, the Foucaultian epistemology has a great deal to contribute to the study of 
IS phenomena (Willcocks 2006) and the knowledge-related challenges posed within different socio-political contexts. Furthermore, we discussed the asymmetrical nature of the outsourcing market focusing on the resulting increased leverage of the supplier. However, in the long term, one should consider the consequences of what ultimately constitutes a knowledge mismatch for the outsourcing market as a whole. Under this spectrum, it is arguable that the expected long-term benefits cannot be realized by either party.

It can be argued that what is needed in the outsourcing market is a shift of the focus from a unilateral to a reciprocal approach in considering outsourcing needs, services, and outsourcing maturity. Developing the meta-capabilities of the client must involve organizational learning that imports knowledge from beyond the organizational boundaries. In this context, the value of third arty validation mechanism for the client lies not only in pinpointing the organization's outsourcing capabilities, but moreover in engaging it in a process of self-assessment that will ultimately stimulate organizational learning.

\section{Acknowledgements}

The author wishes to acknowledge the contribution and support of Chris Tofts and Richard Taylor, both from HP Labs Bristol.

\section{References}

Burgess, S. 2001. "The Beauty of the Peacock Tail and the Problems with the Theory of Sexual Selection," TJ Magazine (15:2), pp. 94-102.

Cronin, H. 1991. The Ant and the Peacock, Cambridge, UK: Cambridge University Press.

Cullen, S., and Willcocks, L. P. 2003. Intelligent IT Outsourcing: Eight Building Blocks to Success, Amsterdam: Elsevier.

DiRomualdo, A., and Gurbaxani, V. 1998. "Strategic Intent for IT Outsourcing," Sloan Management Review (39:4), pp. 67-80.

Kern, T., Willcocks, L. P., and van Heck, E. 2002. "The Winner's Curse in IT Outsourcing: Strategies for Avoiding Relational Trauma," California Management Review (44:2), pp. 47-69.

Komporozos-Athanasiou, A. 2006. "The Client Outsourcing Maturity Model as a Mechanism for Investigating IT Outsourcing Relationships in the Public Sector," HP Lab Tech Report (HPL2006-169).

Komporozos-Athanasiou, A. 2007. "Assessing Client Maturity: A Key to Successful Outsourcing," HP Labs Technical Report (HPL-2007-124).

McFarlan, W. F., and Nolan, R. L. 1995. "How to Manage an IT Outsourcing Alliance," Sloan Management Review (39:4), pp. 67-80.

Merali, Y. 2002. "The Role of Boundaries in Knowledge Processes," European Journal of Information Systems (11:1), pp. 47-60.

Nonaka, I., and Noboru, K. 1998. "The Concept of 'Ba': Building a Foundation for Knowledge Creation," California Management Review (43:3), pp. 40-54.

Perez-Hallerbach, I. "Assessing the IT Outsourcing Maturity of Organizations: The Case of a Large Consumer Products Company,” HP Labs Technical Report (HPL-2007-36).

Taylor, R., and Tofts, C. 2005. "Death by a Thousand SLAs: A Short Study of Commercial Suicide Pacts," HP Lab Tech Report (HPL-2005-11).

Taylor, R., and Tofts, C. 2008. "Model Based Services Discovery and Management Industrial Research and Practice Paper," HP Lab Technical Report (HPL-2008-19). 
Taylor, R., Tofts, C., and Yearworth, M. 2004. “Open Analytics,” HP Labs Tech Report (HPL2004-138).

Venkatraman, N. 1997. "Beyond Outsourcing: Managing IT Resources as a Value Center," Sloan Management Review (38:3), pp. 51-54.

Willcocks, L. P. 2006. "Michel Foucault in the Social Study of ICTs: Critique and Reappraisal," Department of Information Systems Working Paper Series \#138, London School of Economics and Political Science.

Willcocks, L. P., and Lacity, M. 2006. Global Sourcing of Business and IT Services, London: Palgrave Macillan 2006.

\section{About the Author}

Aris Komporozos-Athanasiou is an M.Phil. candidate at Judge Business School, University of Cambridge. He holds a B.Sc. in Economics and an M.Sc. in Information Systems from the University of Warwick. Prior to joining Cambridge, he worked as a services science researcher at Hewlett Packard Labs. His research integrates social theory and information systems and his dissertation explores different concepts of agency in the development of collaborative innovation. Aris can be reached at ariskomp@yahoo.gr. 